http://zoobank.org/urn:lsid:zoobank.org:pub:DF345B6E-DF9A-448E-B0DE-A45ED0309AA0

\title{
Palms and pollen beetles: two new anthophilous beetle species of Meligethinus from Mozambique (Coleoptera: Nitidulidae: Meligethinae)
}

\author{
SIMONE SABATELLI ${ }^{1}$, MEIKE LIU ${ }^{2,6}$, ANDREW RICHARD CLINE ${ }^{3}$, ANDRZEJ LASON ${ }^{4}$, \\ SUZANA MACUVELE ${ }^{5}$, KISIMENDA MUAMBALO ${ }^{5}$, LUCILIA CHUQUELA $^{5}$ \& PAOLO AUDISIO ${ }^{1}$ \\ 'Dipartimento di Biologia e Biotecnologie "Charles Darwin”, Sapienza Università di Roma, Rome, Italy \\ ${ }^{2}$ College of Agriculture, Yangtze University, Jingzhou, China \\ ${ }^{3}$ Plant Pest Diagnostics Center, California Department of Food \& Agriculture, Sacramento, CA, USA \\ ${ }^{4} u l$. Wiejska 4B/85, 15-352 Bialystok, Poland \\ ${ }^{5}$ Museu de História Natural, Universidade Eduardo Mondlane, Travessia do Zambeze 104, Maputo 1100, Mozambique \\ ${ }^{6}$ Corresponding author. $\equiv$ liumk2009@126.com
}

\begin{abstract}
The genus Meligethinus Grouvelle, 1906 represents a small group of pollen beetles, including some twenty species distributed from southern Palaearctic areas to northern Oriental and Afrotropical regions. All constituent species appear to be strictly associated as larvae and adults to male inflorescences of palms (Monocots: Arecaceae). Two new species of this genus (Meligethinus mondlanei sp. nov. and M. hamerlae sp. nov.) were recently discovered in southern Mozambique, and are described herein. Both are associated as larvae with male inflorescences of the widespread eastern African palm Phoenix reclinata Jacq. The two new species are compared with related taxa from central Africa. Additionally, the presence of additional species of the same genus in southern Mozambique is reported, and the local associations of several Meligethinus species are discussed.
\end{abstract}

Key words: taxonomy, larval host-plants, Afrotropical, Cucujoidea

\section{Introduction}

The important subfamily Meligethinae (Coleoptera: Nitidulidae) comprises some 700 pollen-feeding species worldwide (Audisio 1993; Audisio et al. 2009b; Jelínek et al. 2010; Cline et al. 2014).

The genus Meligethinus was formally established by Grouvelle (1906), based on the species M. humeralis Grouvelle, 1906 from Angola, by monotypy (Grouvelle 1919; Cooper 1980). As recently delimited by Audisio et al. (2009b), Meligethinus includes some twenty species distributed from western Mediterranean areas (including Maghreb) to the northern Arabian Peninsula and Iran, tropical and subtropical Africa, eastern Palaearctic areas (S China and Japan; Hisamatsu 2019) and the Oriental Region (Indian subcontinent and Indochina). Two major diversity hotspots for this clade are located in southeastern tropical Africa and northwestern Oriental regions. All Meligethinus species are associated with male inflorescences (spates) of palms (Arecaceae) as larvae (Audisio 1993; De Marzo 2002); adults are also rarely found away from them. The majority of species are mostly monophagous, although some are oligophagous (Audisio 1993; Jelínek 1992; Audisio et al. 2009b; De Marzo 2002; Kirejtshuk 2012; Liu et al., unpublished data). A global taxonomic revision of this genus is in preparation (Sabatelli et al., unpublished data), including phylogenetic inferences based on a molecular analysis (Trizzino et al. 2009).

Herein, we describe two new species of Meligethinus recently discovered in southeastern Mozambique (Fig. 3) during other research for the Project of International Cooperation funded by Program of Italian Development Cooperation Agency (projects AID10524-AID11096-AICS MAPUTO; see below in Acknowledgements). These research endeavors have mostly been aimed at collecting representatives of pollen beetles associated with palms (Arecaceae), Lamiaceae, Fabaceae, Sterculiaceae, and Asteraceae-Tarchonantheae (Audisio 1996; Audisio et al. 1998, 2009a, 2015; Audisio \& De Biase 2004), which represent the most dominant and significant plant taxa in the densely populated and low-altitude areas of southern Mozambique. 


\section{Depositories}

Acronyms of museum institutions and personal collections are as follows:

ACC-Andrew Cline Collection, Sacramento, CA, USA

CAS - Collection of the California Academy of Sciences, San Francisco, CA, USA

CAR-MZUR - P. Audisio Collection, currently housed in the Zoological Museum, Sapienza Rome University,

Rome, Italy

CLA-Collection A. Lasoń, Białystok, Poland

IZAS - Institute of Zoology, Chinese Academy of Sciences, Beijing, China

MHNMM-Museu de Historia Natural Maputo, Maputo

NMPC — National Museum (Natural History), Prague, Czech Republic

\section{Diagnoses and descriptions of new species}

\section{Meligethinus mondlanei sp. nov.}

(Figs 1a-b, g, j, 1, Fig. 2)

Diagnosis. Narrowly elongate, scarcely transversely convex, uniformly testaceous-orange; similar in habitus shape to the Oriental Meligethinus plagiatus (Grouvelle, 1894) (from NE India to N Vietnam and S China, including Taiwan), as well as to the sympatric M. hamerlae sp. nov. and M. suffusus Kirejtshuk, 1980. This species is easily differentiated by the peculiarly shaped metatibiae in males, and the different shape of male and female genitalia.

Description (male holotype). Size: body length $2.2 \mathrm{~mm}$, width $1.08 \mathrm{~mm}$. Body narrowly elongate, scarcely transversely convex, uniformly testaceous-orange (Fig. 2). Dorsal surface rather densely, finely and shallowly punctate (spaces between pronotal and elytral punctures $\sim 1.5-2 \times$ diameter of puncture), with dull and shagreened interspaces; elytra without traces of transverse strigose sculpturing. Pronotum trapezoidal with widely arcuate lateral sides, maximum width near posterior five-sixths (Fig. 2). Pubescence on pronotum and elytra sparse, golden-whitish, moderately long and distinct, each seta markedly shorter than antennomere 6 , slightly longer along posterior base. Body uniformly orange-yellowish, without pale or dark areas, including peripheral margins (pronotal carina) of pronotum; legs and antennae uniformly yellowish-orange testaceous, with antennal club distinctly darker and pale brown. Antennal club elongate, symmetrical (Fig. 2). Proximal base of pygidium with normal, "V" shaped impression along midline, directed posteriad. Median flat portion of prosternal process broadly rounded distad, nearly parallel-sided, maximum width near distal $2 / 5$. Metaventrite with a moderately deep, nearly pentagonal impression, occupying posterior two-thirds of the metaventrite, impression deeper longitudinally along middle. Last abdominal ventrite bearing two moderately large proximal semicircular impressions, diameter nearly $1 \times$ the maximum diameter of an eye.

Legs: Protibia (Fig. 1j) wide, triangular, protarsi nearly as wide as length of antennomere 3; ratio WFTA/LFTA $\approx 0.25$. Mesotibia (Fig. 2) wide, trapezoid-like. Metatibia (Fig. 1-1) moderately wide, peculiarly shaped, their inner side strongly modified and narrowed at posterior half, markedly denticulate, distinct from any other known member of the genus.

Male genitalia: distinctly shaped, rather small, with elongate and subparallel-sided tegmen, slightly convergent distad (Fig. 1a), parameres with roundly pointed apex; ratio DTIN/LETE $\approx 0.60-0.65$, excised inner margins without projections; ratio LETE/WITE $=1.45-1.50$. Aedeagal median lobe peculiarly shaped, markedly narrowed in distal third, maximum width near distal third; distinctly truncate and chisel-shaped distad (Fig. 1b); ratio LEAE/ WIAE $=1.80-1.90$. Main sclerites of internal sac (endophallus) small and rod-shaped in dorsal and lateral view.

Female: Antennae similar in both sexes. Protibia rather wide, triangular, slightly narrower than males, protarsus slightly narrower than males (ratio WFTA/LFTA $\approx 0.20$ ). Mesotibia wide, trapezium-like as in males. Metatibia almost simple and uniformly narrower than in males, not denticulate, or arcuately incised along inner side. Metaventrite in females almost flat, without distinct impression, medially with a scarcely impressed longitudinal line. Ovipositor rather small and lightly sclerotized, not darkened towards moderately blunt distal apex, styli long, inserted close to apex (Fig. $1 \mathrm{~g}$ ). Ratio STLE/DSIA $\approx 0.50$; ratio STLE/CGOW $\approx 0.25$; ratio GONL/CGOW $\approx 3.1$. Ratio OVPL/GONL $\approx 1.80$. 
Variation: The overall body size $2.0-2.7 \mathrm{~mm}$ (length) and $1.05-1.25 \mathrm{~mm}$ (width) can be variable between individuals.

Examined material. Holotype, male: Mozambique: Maputo Province, Inhaca Island, Farol, 10-15 m a.s.1., $25^{\circ} 58^{\prime} 22^{\prime}$ 'S, 3259'08'E, 21.ix.2018, P. Audisio \& S. Sabatelli lgt, sparsely forested and bushy area, beating male inflorescences of Phoenix reclinata Jacq. (Arecaceae) (MHNMM). Paratypes: 35 males, 32 females; same locality, 27.ix.2019, S. Sabatelli lgt, 10 males, 9 females (MHNMM, CAR-MZUR, CAS, CLA, ACC, NMPC); same local-

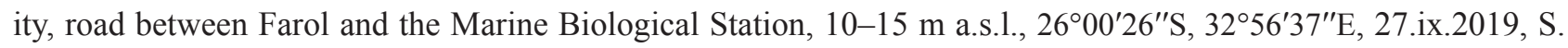
Sabatelli lgt, open and sparsely bushy area, beating male inflorescences of Phoenix reclinata Jacq. (Arecaceae), 5 males, 6 females (MHNMM, CAR-MZUR); Maputo Province, Maputo Special Reserve, Chingute Lake, 10-15 m

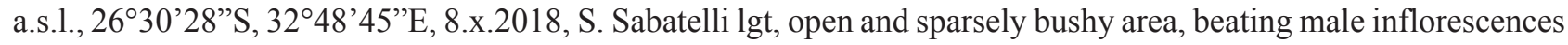
of Phoenix reclinata Jacq. (Arecaceae), 2 males, 2 females (MHNMM, CAR-MZUR); Maputo Province, Zitundo, 26 40'44'S, 32 $47^{\circ}$ '55'E, 14.ix.2019, S. Sabatelli lgt, open and sparsely bushy area, beating male inflorescences of Phoenix reclinata Jacq. (Arecaceae), 18 males, 15 females (MHNMM, CAR-MZUR).

Distribution. This species is known only from southern Mozambique (Fig. 3). The host plant Phoenix reclinata is widespread in eastern portions of central and southern Africa, northwards to southern Egypt and southwards to the Eastern Cape Province in South Africa (Coates Palgrave 2002; see also pza.sanbi.org/phoenix-reclinata). The geographic range could potentially be wider, including at least parts of these areas.

Host plants. In Mozambique, this species appears to be strictly associated with male inflorescences of Phoenix reclinata Jacq. (Arecaceae).

Habitat. Locality data indicate this species prefers the edges of sparsely forested and bushy areas, in sandy habitats close to the sea, at low altitudes. All specimens of the type series were collected by sweeping flowering males of Phoenix reclinata in conjunction with the more abundant Meligethinus dolosus and M. peringueyi, as well as a few specimens of the locally less abundant M. hamerlae sp. nov., M. suffusus, and M. humeralis.

Phenology. Specimens were collected in middle and late September, which likely indicates adult activity from late August to early October.

Etymology. The specific epithet is derived from the current name of the University of Maputo, the former "University of Lourenço Marques", which, after Mozambique became independent in 1975, was renamed in honor of Frelimo leader Eduardo Mondlane in 1976. We are honored to name this remarkable new species from the name of this University, in consideration of the collaborative activities of international cooperation with the Rome Sapienza University.

Taxonomic remarks. This new species is vaguely similar in external shape to the Oriental M. plagiatus from northeastern India, northern Vietnam and southern China and to the African and sympatric M. suffusus and M. hamerlae sp. nov. (see below). However, the new species is distinguished by the peculiar shape of the male metatibiae and male genitalia, as well as the distinctly shaped female ovipositor.

\section{Meligethinus hamerlae sp. nov.}

(Figs 1e-f, i, p)

Diagnosis. Narrowly elongate, moderately transversely convex, uniformly testaceous-orange. Similar in external shape and color to $M$. mondlanei sp. nov. described above and similar to the sympatric $M$. suffusus, but easily differentiated from the former by the markedly distinct shape of metatibiae in males, and the different shape of male and female genitalia, as well as the presence of a small dorsal, medial, pre-distal projection on the female pygidium. The new species is easily differentiated from the latter by the presence of the medial projection on the female pygidium, by the markedly distinct shape of male genitalia, and the usually paler body color. This new species is likely closely related to the central African M. muehlei Jelínek, 1992, which is on average larger and darker, characterized by completely different male metatibiae, a markedly larger and longer pygidial female projection, and distinctively shaped male and female genitalia.

Description. (male holotype). Size: body length $2.4 \mathrm{~mm}$, width $1.10 \mathrm{~mm}$. Body narrowly elongate, scarcely transversely convex, uniformly testaceous-orange. Dorsal surface rather densely, finely and shallowly punctate (spaces between pronotal and elytral punctures $\sim 1.5-2 \times$ diameter), with dull and shagreened interspaces; elytra without traces of transverse strigose sculpturing. Pronotum trapezoidal in shape, with widely arcuate lateral sides, 
maximum width near posterior five sixths. Pubescence on pronotum and elytra sparse, golden-whitish, moderately long and distinct, each seta markedly shorter than antennomere 6, slightly longer along posterior base. Body uniformly orange-yellowish, without pale areas, including peripheral margins (pronotal carina) of pronotum; legs and antennae uniformly yellowish-orange, testaceous, with antennal club distinctly darker, pale brown. Antennal club elongate, symmetrical, without differences between sexes. Proximal base of pygidium with normal, "V" shaped medial impression, directed posteriad. Prosternal process broadly rounded distad, maximum width near distal 2/5. Metaventrite almost flat, only slightly depressed in posterior half, with a scarcely distinct longitudinal impression. Last abdominal ventrite bearing two rather small proximal semicircular impressions, diameter nearly $1.2 \times$ the diameter of an eye.

Legs: protibia (Fig. 1k) wide, triangular, as in M. suffusus Kirejtshuk, 1980, protarsus nearly as wide as length of antennomere 3 (ratio WFTA/LFTA $\approx 0.25$ ). Mesotibia wide, trapezoid shaped. Metatibia (Fig. $1 \mathrm{~m}$ ) scarcely wide, along inner side almost simple and regular in posterior half, not denticulate, almost identical to that of $M$. suffusus Kirejtshuk, 1980, exhibiting no marked sexual dimorphism.

Male genitalia: distinctively shaped, with elongate and subparallel-sided tegmen (Fig. 1e), aedeagal median lobe rather small, maximum width at proximal fifth, ratio LEAE/WIAE = 2.15-2.20 (Fig. 1f); aedeagal apex narrowly truncate with a distinct and narrowly chisel-shaped distal apex, $\sim 1 / 5$ as wide $(0.20 \times)$ as maximum basal aedeagal width (Fig. 2f). Ratio DTIN/LETE $\approx 0.44-0.48$, median excision of tegmen narrow along first four-fifths of its length; ratio LETE/WITE $=1.40-1.42$.

Female: Protibia rather wide, triangular, slightly narrower than males, protarsus slightly narrower than males (ratio WFTA/LFTA $\approx 0.22$ ). Mesotibia wide, trapezoid as in males. Metatibia simple and uniformly slightly narrower than males, along inner side almost rectilinear and not denticulate. Pygidium with a small but distinct median obliquely positioned conical protuberance directed posteriad, similar to females of Meligethinus muehlei from Rwanda (Jelínek 1992; Fig. 1n), but smaller (Fig. 1p). Ovipositor rather small and moderately sclerotized, not darkened toward the moderately blunt distal apex, exhibiting short styli, similar to that exhibited by M. suffusus (Kirejtshuk 1980; Fig. 1h), although exhibiting a slightly narrower distal gonocoxal apex (Fig. 1i). Ratio STLE/DSIA $\approx$ 0.40 ; ratio $\mathrm{STLE} / \mathrm{CGOW} \approx 0.17$; ratio GONL/CGOW $\approx 3$. Ratio $\mathrm{OVPL} / \mathrm{GONL} \approx 2.15$.

Variation: Overall body sizes range from 1.9-2.6 mm (length) and 0.90-1.20 mm (width).

Examined material. Holotype, male: Mozambique: Maputo Province, Inhaca Island, Farol, 10-15 m a.s.l., $25^{\circ} 58^{\prime} 22^{\prime}$ 'S, 32 $59^{\prime} 08^{\prime \prime}$, 21.ix.2018, P. Audisio \& S. Sabatelli lgt, sparsely forested and bushy area, beating male inflorescences of Phoenix reclinata Jacq. (Arecaceae) (MHNMM). Paratypes: 10 males, 13 females; same data as holotype, 2 males, 2 females (MHNMM, CAR-MZUR); same locality, 27.ix.2019, S. Sabatelli lgt, open and sparsely bushy area, beating male inflorescences of Phoenix reclinata Jacq. (Arecaceae), 6 males, 8 females (MHNMM, CAR-MZUR, CAS, CLA, ACC, NMPC); same locality, road between Farol and the Marine Biological Station, 10-15 m a.s.1., $26^{\circ} 00^{\prime} 26^{\prime \prime}$ S, 32 $56^{\prime} 37^{\prime \prime} E, 27 . i x .2019$, S. Sabatelli lgt, open and sparsely bushy area, beating male inflorescences of Phoenix reclinata Jacq. (Arecaceae), 2 males, 3 females (NMMU, CAR-MZUR).

Distribution. This species is known from Inhaca Island in southern Mozambique (Fig. 3). The host-plant Phoenix reclinata is widespread in Eastern Africa (see above information on M. mondlanei sp. nov.; Coates Palgrave 2002; see also pza.sanbi.org/phoenix-reclinata). The geographic range could be wider, potentially including at least part of these areas. However, several attempts (2018-2019) aimed to collect M. hamerlae sp. nov. in nearby localities of continental southeastern Mozambique near Maputo failed in producing any additional specimens. The apparently exclusive presence of this new species at Inhaca is odd, considering this small island is separated from coastal areas of southeastern Mozambique by a shallow sea that did not create a barrier with the mainland during the most recent Würm Glaciation.

Host-plants. This species appears to be strictly associated with male inflorescences of Phoenix reclinata Jacq. (Arecaceae). All specimens of the type series were collected by sweeping flowering males in conjunction with the more abundant Meligethinus dolosus, M. peringueyi, and M. suffusus, as well as a few specimens of the locally less abundant M. mondlanei sp. nov., and M. humeralis.

Habitat. Locality data indicate this species prefers edges of sparsely forested and bushy areas, in sandy habitats close to the sea at very low altitudes.

Phenology. The few available specimens were collected in middle and late September, which likely indicates adult activity from late August to early October. 


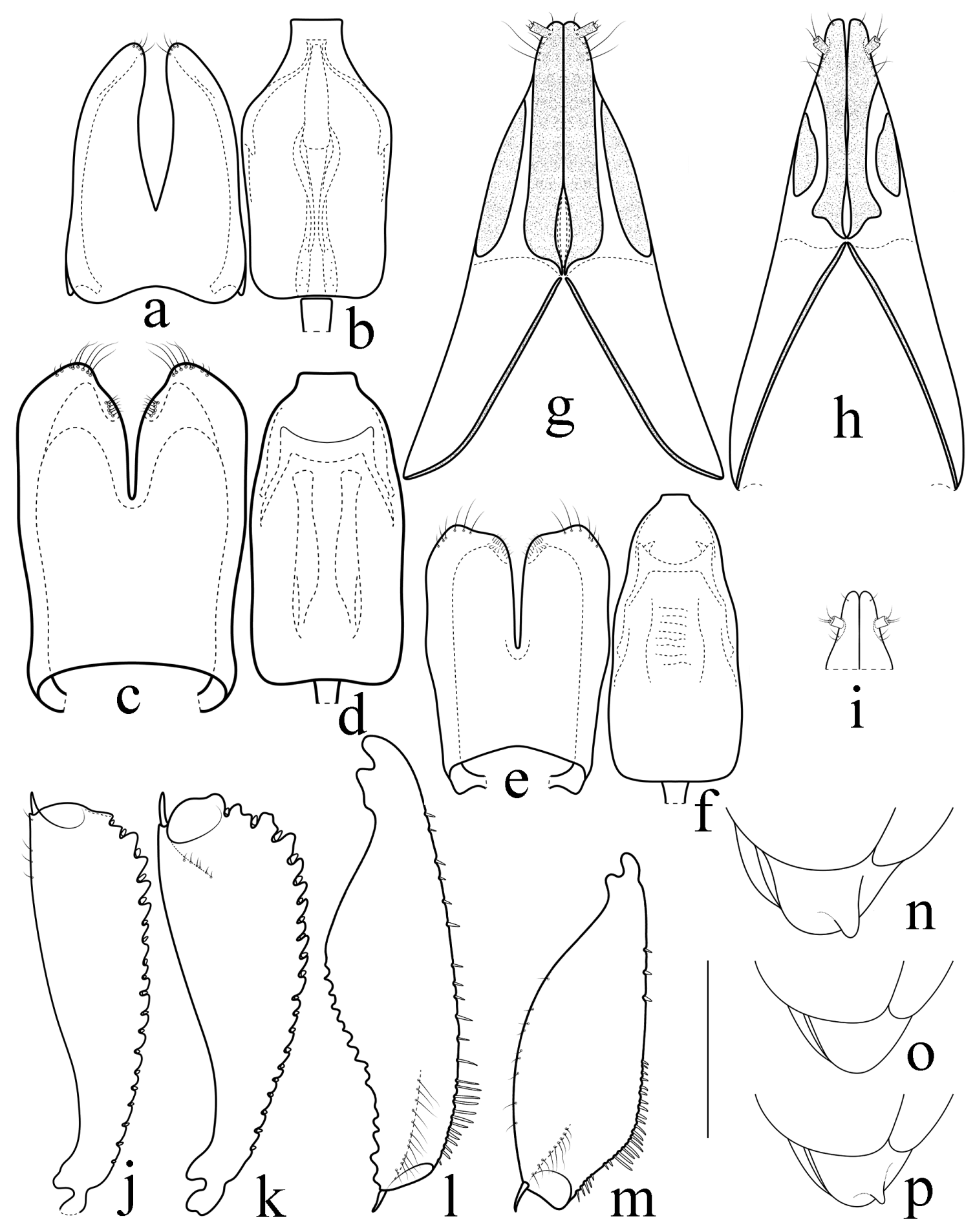

FIGURE 1. Male genitalia (tegmen and median lobe of the aedeagus) of Meligethinus spp.: a-b, Meligethinus mondlanei $\mathbf{s p .}$ nov., male paratype from Inhaca Island, Mozambique; c-d, Meligethinus suffusus, male from Inhaca Island, Mozambique; e-f, Meligethinus hamerlae sp. nov., male paratype from Inhaca Island, Mozambique; ovipositor (ventral view) of Meligethinus spp. (i: distal apex only): g, Meligethinus mondlanei sp. nov., female paratype from Inhaca Island, Mozambique; h, Meligethinus suffusus Kirejtshuk, 1980, female from Inhaca Island, Mozambique; i, Meligethinus hamerlae sp. nov., female paratype from Inhaca Island, Mozambique; front tibiae of Meligethinus spp.: j, Meligethinus mondlanei sp. nov., male paratype from Inhaca Island, Mozambique; k, Meligethinus suffusus, male from Inhaca Island, Mozambique; hind tibiae of Meligethinus spp.: I, Meligethinus mondlanei sp. nov., male paratype from Inhaca Island, Mozambique; m, Meligethinus suffusus, male from Inhaca Island, Mozambique; dorso-lateral view of the elytral apices and of female pygidium of Meligethinus spp.: n, Meligethinus muehlei from Kibuye, Rwanda; o, Meligethinus suffusus from Inhaca Island, Mozambique; p, Meligethinus hamerlae sp. nov., female paratype from Inhaca Island, Mozambique. Scale bar: $0.2 \mathrm{~mm}$ (Figs a-m); 0.5 mm (Figs n-p). 


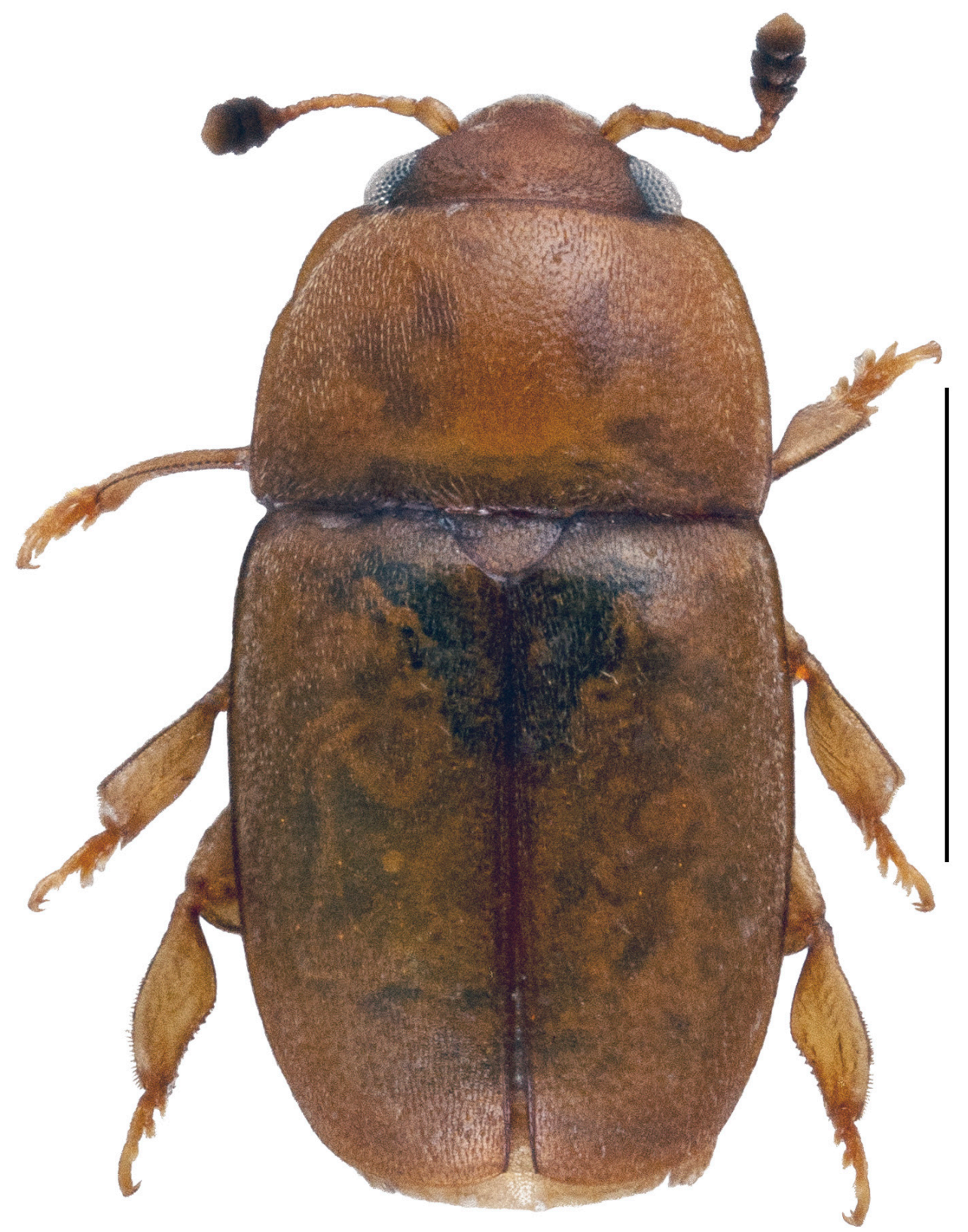

FIGURE 2. Habitus of Meligethinus mondlanei sp. nov., male paratype from Inhaca Island, Mozambique. Scale bar: $1 \mathrm{~mm}$. Photo by Gareth Powell and Seth Bybee, Provo, USA.

Etymology. The specific epithet honors Maria Grazia Hamerl, mother of the senior author S. Sabatelli.

Taxonomic remarks. As reported above, this new species is similar in external shape to the sympatric $M$. mondlanei sp. nov. and especially to the sister species M. suffusus (see below), being otherwise unmistakable due to the peculiar shape of the female pygidium (Fig. 1p), and the distinctly different shape of the male genitalia (Figs 1e-f), in particular the distinctly more narrowly chisel-shaped distal apex of the aedeagus (distinctly wider in $M$. suffusus: Figs 1c-d). The shared presence of a pre-distal conical protuberance on the female pygidium also suggests a close taxonomic relationship of the new species to the larger Meligethinus muehlei from Rwanda (Jelínek 1992), which is easily differentiated from the new species by the different male and female genitalia, a much larger size of the pygidial conical protuberance in females (Fig. 1n), darker body color with large, dark brown elytral spots, and longer golden hairs on legs in males (Jelínek 1992). Preliminary molecular analyses of the genus Meligethinus (Sabatelli et al., unpublished data) demonstrates that the sympatric and syntopic M. hamerlae sp. nov. and M. suffusus are sister species, amply separated by an average genetic $p$-distance (COI gene) of $\approx 0.6$, indicating a well-established specific differentiation, combined with a clear common origin from a shared most recent ancestor. 


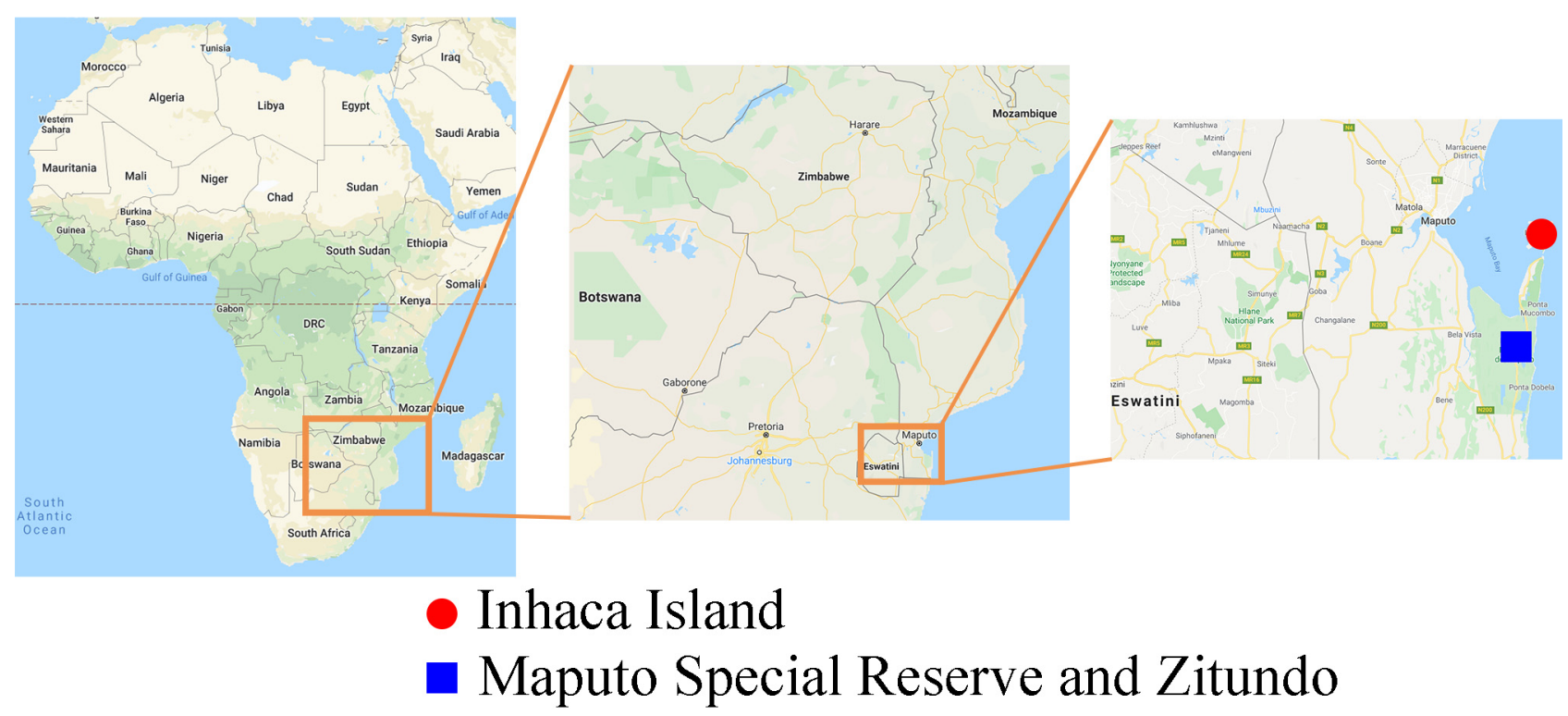

FIGURE 3. Map of Mozambique and location of the two studied areas where the new species of Meligethinus have been discovered.

\section{Meligethinus associations in southern Mozambique}

To complete the objectives of the Project of Italy-Mozambique scientific Cooperation, we recently performed research (2017-2019) on a number of palm (Arecaceae) areas in southern Mozambique to search for Meligethinae. Until now, only the widespread palm species Phoenix reclinata Jacq. has been demonstrated to host Meligethinae. The two new species co-occur syntopically on male flowers of the same Phoenix reclinata trees in Inhaca Island, also in company with M. suffusus (Sabatelli et al., unpublished data), and with three more Meligethinus species.

Further research is planned to search for Meligethinae specimens on other widespread flowering palm species, such as Hyphaene petersiana Klotzsch ex Mart., 1845, on the potentially autochthonous (and widely cultivated elsewhere in central Africa) Elaeis guineensis Jacq. (see Jelínek 1992), and especially on the rare and threatened giant palm Raphia australis Oberm. \& Strey, which is endemic to this region (Maputo area in Mozambique and Kosi Bay area in northern KwaZulu-Natal). The giant inflorescences are produced once in its lifetime and are temporally unpredictable (Coates Palgrave 2002), but are most likely to occur during spring.

The following is a list of Meligethinus species collected in southeastern Mozambique on male specimens of Phoenix reclinata. The collecting localities are listed in Table 1 (geographic details and data are in the examined material for the two new species described). Table 1 also reports the percentages of each Meligethinus species (with numbers of individuals) found in each locality: M. dolosus Grouvelle, 1919, M. hamerlae sp. nov., M. humeralis Grouvelle, 1906, M. mondlanei sp. nov., M. peringueyi (Grouvelle, 1919), and M. suffusus Kirejtshuk, 1980.

TABLE 1. Meligethinus species collected in Maputo Province, southern Mozambique (2018-2019) on male inflorescences of the palm Phoenix reclinata Jacq. TN: Total number of collected specimens. Number of specimens cumulatively collected in the two study areas near Maputo are reported along with associated corresponding percentages.

\begin{tabular}{|c|c|c|c|c|c|c|c|}
\hline Locality & TN & dolosus & peringueyi & mondlanei & suffusus & hamerlae & humeralis \\
\hline $\begin{array}{l}\text { Maputo Province, Inhaca } \\
\text { Island (6 cumulative sam- } \\
\text { plings) }\end{array}$ & 533 & $151(28 \%)$ & $186(35 \%)$ & $31(6 \%)$ & $105(20 \%)$ & $24(4 \%)$ & $36(7 \%)$ \\
\hline $\begin{array}{l}\text { Maputo Province, Ma- } \\
\text { puto Special Reserve and } \\
\text { Zitundo ( } 4 \text { cumulative } \\
\text { samplings) }\end{array}$ & 427 & $118(28 \%)$ & $108(25 \%)$ & 37 (9\%) & $120(28 \%)$ & - & $44(10 \%)$ \\
\hline
\end{tabular}


Percentages of each species are similar in the two studied areas, with the only exception of M. hamerlae sp. nov., which is apparently absent outside Inhaca Island (where it is the rarest species). Meligethinus dolosus, M. peringueyi, and M. suffusus appear to be the dominant species, while the remaining taxa (M. mondlanei sp. nov. and M. humeralis) are more marginally represented in our collecting efforts.

\section{Acknowledgements}

The authors are grateful to Mauro M. Colombo, Elisa Taviani and Piero Cappuccinelli (Dept. of Biomedical Sciences, Univ. of Sassari, Italy) as well as to the whole staff of the Museu de História Natural de Maputo. The research was supported by the Project "Training in Biodiversity and Biotechnology for sustainable development" AID 11096AICS MAPUTO funded by the Italian Agency of Cooperation for Development, Italy. We thank our colleague Paolo Colangelo for his help with fieldwork. Thanks also to Gareth Powell and Seth Bybee (Brigham Young University, Provo, USA) for the image in Fig. 2, made during their recent visit to PA's Laboratory in Rome.

\section{References}

Audisio, P. (1993) Coleoptera Nitidulidae-Kateretidae. Fauna d'Italia. Vol. 32. Calderini Edizioni, Bologna, xvi + 971 pp.

Audisio, P. (1996) New and little-known South African Meligethes Stephens of the M. convexus group (Coleoptera: Nitidulidae: Meligethinae). African Entomology, 4 (2), 213-230.

Audisio, P., Cline, A.R., De Biase, A., Antonini, G., Mancini, E., Trizzino, M., Costantini, L., Strika, S., Lamanna, F. \& Cerretti, P. (2009a) Preliminary re-examination of genus-level taxonomy of the pollen beetle subfamily Meligethinae (Coleoptera: Nitidulidae). Acta Entomologica Musei Nationalis Pragae, 49, 341-504.

Audisio, P., Cline, A.R., Lamanna, F., Trizzino, M., Antonini, G., Mancini, E. \& De Biase, A. (2009b) Revision of the southern African pollen beetle genus Anthystrix (Coleoptera: Nitidulidae: Meligethinae). Annals of the Entomological Society of America, 102, 998-1016. https://doi.org/10.1603/008.102.0609

Audisio, P., Cline, A.R., Trizzino, M., Mancini, E., Antonini, G., Sabatelli, S. \& Cerretti, P. (2015) Revision of the African pollen beetle genera Tarchonanthogethes and Xenostrongylogethes, with insect-host plant relationships, identification key, and cladistic analysis of the Anthystrix genus-complex (Coleoptera: Nitidulidae: Meligethinae). Zootaxa, 3920 (1), $101-152$. https://doi.org/10.11646/zootaxa.3920.1.6

Audisio, P. \& De Biase, A. (2004) The South African Meligethes of the M. amplicollis-complex (Coleoptera: Nitidulidae: Meligethinae). African Entomology, 12 (2), 231-242.

Audisio, P., Kirk-Spriggs, A. \& Kirejtshuk, A.G. (1998) The Meligethes of the M. pubescens species-group from southern Africa (Coleoptera: Nitidulidae, Meligethinae). Entomologica scandinavica, 29, 169-198. https://doi.org/10.1163/187631298X00276

Cline, A.R., Smith, T.R., Miller, K., Moulton, M., Whiting, M. \& Audisio, P. (2014) Molecular phylogeny of Nitidulidae: assessment of subfamilial and tribal classification and formalization of the family Cybocephalidae (Coleoptera: Cucujoidea). Systematic Entomology, 39, 758-772. https://doi.org/10.1111/syen.12084

Coates Palgrave, K. (2002) Trees of Southern Africa. Struik Publishers, Cape Town, 1212 pp.

Cooper, M.C. (1980) Species of the genus Meligethinus Grouvelle (Coleoptera: Nitidulidae). Entomologica Scandinavica, 11, 32-36. https://doi.org/10.1163/187631280X00301

De Marzo, L. (2002) Valutazione del numero di stadi larvali in Meligethinus pallidulus (Erichson) e in altre quattro specie di nitidulidi (Coleoptera). Bollettino del Laboratorio di Entomologia Agraria Filippo Silvestri, Napoli, 57, $103-111$.

Grouvelle, A. (1906) Nitidulides nouveaux du British Museum [Col.]. Bulletin de la Société Entomologique de France, 75, 201-203. https://doi.org/10.5962/bhl.part.22261

Grouvelle, A. (1919) Descriptions d'espèces nouvelles de Coléoptères de l'Afrique australe. Mémoires Entomologiques, 2, 47-61.

Hisamatsu, S.-T. (2019) Discovery of Meligethinus tschungseni Kirejtshuk from Japan, the most eastward record of the genus Meligethinus Grouvelle (Coleoptera, Nitidulidae, Meligethinae). Elytra, Tokyo, New Series, 9 (1), 117-119.

Jelínek, J. (1992) Nitidulidae (Coleoptera) associated with flowers of oil palm, Elaeis guineensis (Arecales, Arecaceae) in Rwanda. Acta Entomologica Bohemoslovaca, 89, 409-427.

Jelínek, J., Carlton, C.E., Cline, A.R. \& Leschen, R.A.B. (2010) 10.26. Nitidulidae Latreille. In: Leschen, R.A.B., Beutel, R.G. \& Lawrence, J.F. (Eds.), Handbook of Zoology. Arthropoda: Insecta. Coleoptera, Beetles. Vol. 2. Morphology and System- 
atics (Elateroidea, Bostrichiformia, Cucujiformia partim). Walter De Gruyter, Berlin, pp. 390-407. https://doi.org/10.1515/9783110911213.390

Kirejtshuk, A.G. (1980) New species of beetles of the subfam. Meligethinae (Coleoptera, Nitidulidae) from the Ethiopian Region. Revue de Zoologie Africaine, 94, 249-294.

Kirejtshuk, A.G. (2012) Structural diversity of sap beetles of the subfamily Meligethinae (Coleoptera, Nitidulidae) inhabiting palm inflorescences. Abstracts of the XIV Congress of the Russian Entomological Society, Saint Petersburg, 27 August-1 September 2012, 178.

Trizzino, M., Audisio, P., Antonini, G., De Biase, A. \& Mancini, E. (2009) Comparative analysis of sequences and secondary structures of the rRNA internal transcribed spacer 2 (ITS2) in pollen-beetles of the subfamily Meligethinae (Coleoptera, Nitidulidae): potential use of slippage-derived sequences in molecular systematics. Molecular Phylogenetics and Evolution, 51, 215-226.

https://doi.org/10.1016/j.ympev.2008.11.004 